\title{
Neural Network based p-q-r Theory for Harmonic Reduction and Neutral Current Mitigation
}

\author{
S. Malathi, J. Jayachandran \\ Departement of Electrical and Electronics Engineering, SASTRA University, India
}

\begin{tabular}{l}
\hline \hline Article Info \\
\hline Article history: \\
Received May 28, 2017 \\
Revised Nov 3, 2017 \\
Accepted Nov 10, 2017 \\
\hline
\end{tabular}

Keyword:

DSTATCOM

Neural network

Neutral current mitigation

Total harmonic distortion

Unbalanced and/or distorted source

\begin{abstract}
The power quality compensator chosen in this paper is a DSTATCOM which integrates a three phase four leg Voltage Source Converter (VSC) with a DC capacitor. The major role of the DSTATCOM is to mitigate the components of harmonic/reactive current present in the line current thereby shapes the grid current to be sinusoidal and improves the power factor nearly unity under varying conditions. In addition DSATATCOM mitigates neutral current $\left(\mathrm{I}_{\mathrm{sn}}\right)$ and balances the load currents under unbalanced conditions in three phase four wire (3P4W) distribution system. The control strategy proposed for the DSTATCOM is a Neural Network (NN) based p-q-r theory with two Artificial Neural Network (ANN) controllers for a 3P4W distribution system. The reference signal for 3P3W Shunt Active Power Filter (SAPF) is calculated by implementing an ANN controller. The alleviation of $I_{\mathrm{sn}}$ under unbalanced condition is achieved by another ANN controller which produces reference signal for the $1 \Phi$ APF. The performance of the proposed DSTATCOM is analysed for various conditions through simulations in MATLAB SIMULINK and the simulation results justify the effectiveness of the propounded $\mathrm{NN}$ based control algorithm for DSTATCOM.
\end{abstract}

Copyright (c) 2018 Institute of Advanced Engineering and Science. All rights reserved.

Corresponding Author:

S. Malathi,

Departement of Electrical and Electronics Engineering,

SASTRA University,

Thirumalaisamudram, Thanjavur, Tamil Nadu 613401, India.

Email: jj_chandru@eee.sastra.edu

\section{INTRODUCTION}

In earlier days, equipment were robust and insensitive to minor variations in supply voltage. The loads on the earlier electric distribution networks were of non-polluting nature. A major concern in such electric power systems was reactive power support. The development of modern power electronic switching devices has completely changed the load characteristics [1], [2]. Switched Mode Power Supplies (SMPS), arc welding machines, DC and AC drives, Uninterrupted Power Supplies (UPS) etc., are some out of the vast applications of power electronic devices. The operation of these equipment/loads introduces harmonics and contaminate the modern distribution system. These equipment are often insensitive to voltage disturbances; however, they draw currents which are highly distorted in nature. Studies show that such equipment produce distortion in supply voltages [3], [4]. The harmonics and unbalanced currents result in distorted and unbalanced voltages. The pollution on the distribution network is increasing to such an extent that the utility providers can no longer support them. Therefore, the utility imposed strict standards on the industrial and domestic consumers to restrict the harmonic currents that a load may inject into the network. To comply with power quality standards, customers have to introduce mitigation techniques to reduce the extent of pollution caused by their loads and avoid heavy penalties imposed by the utility. There is a necessity to install mitigating equipment that help both the utility and the customer. In such environments, the objective is to protect sensitive equipment from voltage disturbances and at the same time reduce the distortion injected into 
the network. Quality of electrical power can be improved using the following two methodologies. a) Load conditioning and b) Installation of power line conditioners. The former counteracts voltage and current disturbances and the latter limits the circulation of harmonic currents in power distribution system. They are usually custom designed for a particular application [5], [6].

In industries, residential and commercial buildings, the electric power delivered to $1 \mathrm{P} / 3 \mathrm{P}$ loads is mainly by 3P4W distribution system. Even well balanced 1P non-linear loads on a 3P4W system can produce considerable $\mathrm{I}_{\mathrm{sn}}$. Non-linear loads draw non-sinusoidal phase currents. The phasor sum of balanced non-

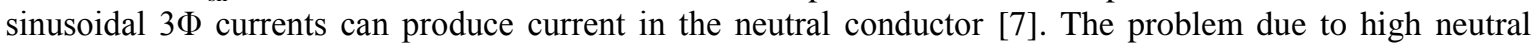
current are: a) Wiring failure b) Common mode noise c) Flat-topping of voltage waveform and d) Overloading of distribution feeders and transformers. Surplus neutral currents can be eliminated by incorporating neutral current compensation techniques. The use of $3 \mathrm{P} 4 \mathrm{~W}$ APF is one of the active solutions which is recommended for the mitigation of neutral current [8], [9].

In this paper, the role of power quality compensator is accomplished through a NN based p-q-r control strategy for 3P4W DSTATCOM. The topology of a DSTATCOM constitutes four leg VSC and a DC capacitor. A separate NN controller is implemented for the fourth leg of VSC to mitigate the neutral current. The main functions of the proposed control strategy are a) To maintain unity power factor and draw sinusoidal current from the source side under any load and source conditions b) To compensate reactive power c) To reduce the \% Total Harmonic Distortion (THD) of source current $\left(\mathrm{I}_{\mathrm{s}}\right)$ and iv) To alleviate neutral current under varying conditions.

\section{PROPOSED NN BASED CONTROL ALGORITHM FOR SAPF}

The Figure 1 represents the schematic diagram of 3P4W DSTATCOM. The NN based p-q-r theory satisfies power conservation theory in the calculation of instantaneous power and the three power components can be controlled independently [10]. The proposed NN based p-q-r theory proves to be superior to all other control strategies for $3 \mathrm{P} 4 \mathrm{~W}$ system both in definition and compensation aspects. The proposed control strategy employs NN blocks which adjust the control variables to satisfy the requirement with advantages of high accuracy and faster response. The control technique implemented has two major functions accomplished by two ANN controllers. (a) ANN controller NN1 is employed for estimating the reference current. It extracts the load real power $(\bar{p})$ and thereby enforces the utility to deliver the real part of the fundamental current. (b) Another ANN controller NN2 is employed for the alleviation of $I_{\mathrm{sn}}$ under unbalanced loads.

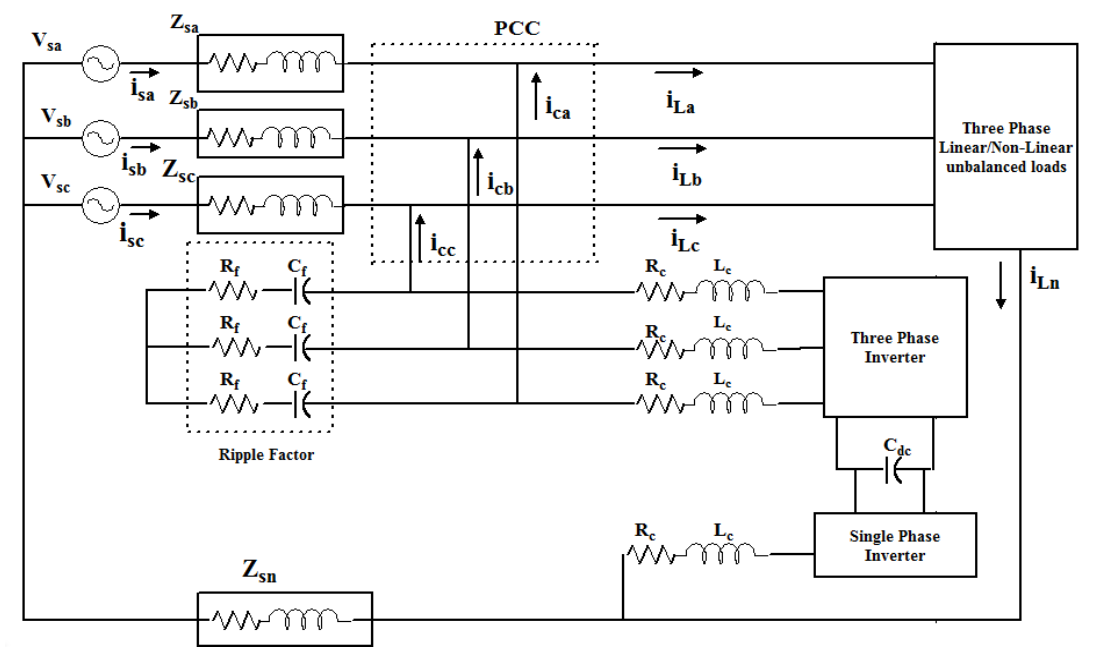

Figure 1. Schematic representation of SAPF

The block diagram of the proposed system is depicted in Figure 2. The p-q-r theory can have smooth control over the supply currents even when the supply voltages are unbalanced and/or distorted and under unbalanced load conditions. The source voltages are sensed and transformed into $\alpha-\beta-0$ coordinates using Equation (1). 


$$
\left[\begin{array}{l}
\mathrm{v}_{0} \\
\mathrm{v}_{\alpha} \\
\mathrm{v}_{\beta}
\end{array}\right]=\sqrt{2 / 3}\left[\begin{array}{ccc}
\frac{1}{\sqrt{2}} & \frac{1}{\sqrt{2}} & \frac{1}{\sqrt{2}} \\
1 & \frac{-1}{2} & \frac{-1}{2} \\
0 & \frac{\sqrt{3}}{2} & -\frac{\sqrt{3}}{2}
\end{array}\right]\left[\begin{array}{c}
\mathrm{v}_{\mathrm{sa}} \\
\mathrm{v}_{\mathrm{sb}} \\
\mathrm{v}_{\mathrm{sc}}
\end{array}\right]
$$

The $\alpha-\beta-0$ coordinates of load currents are calculated from Equation (2).

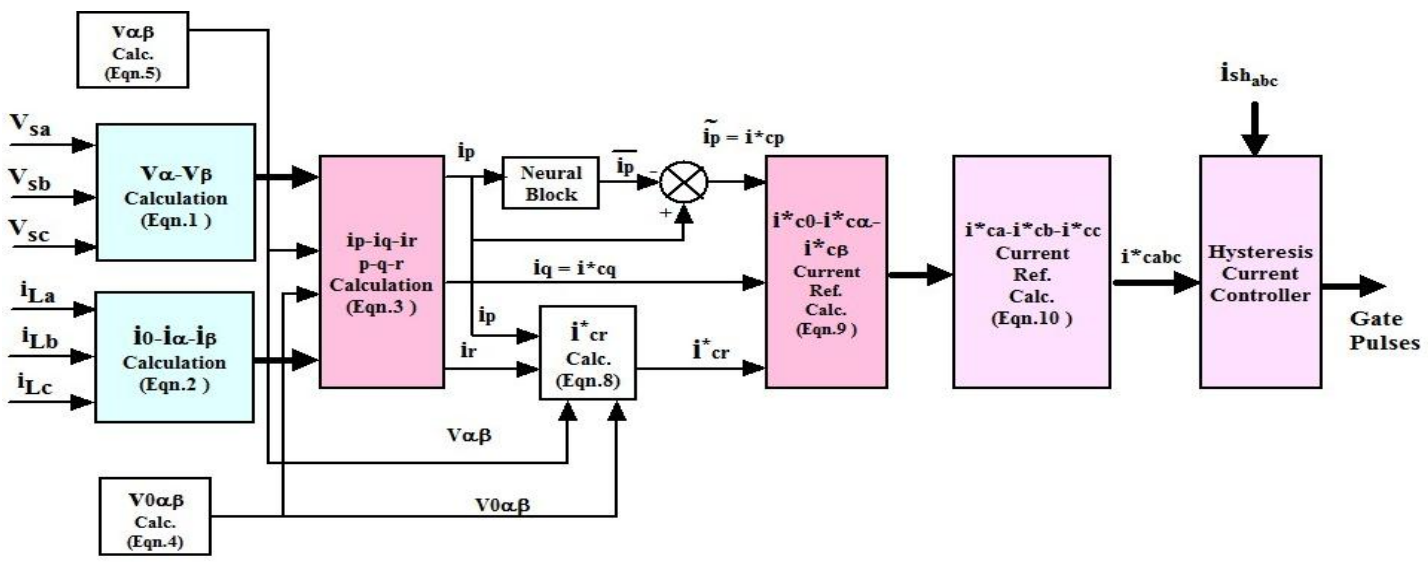

Figure 2. Block diagram of the proposed system

$$
\left[\begin{array}{c}
\mathrm{i}_{0} \\
\mathrm{i}_{\alpha} \\
\mathrm{i}_{\beta}
\end{array}\right]=\sqrt{2 / 3}\left[\begin{array}{ccc}
\frac{1}{\sqrt{2}} & \frac{1}{\sqrt{2}} & \frac{1}{\sqrt{2}} \\
1 & \frac{-1}{2} & \frac{-1}{2} \\
0 & \frac{\sqrt{3}}{2} & -\frac{\sqrt{3}}{2}
\end{array}\right]\left[\begin{array}{l}
\mathrm{i}_{\mathrm{La}} \\
\mathrm{i}_{\mathrm{Lb}} \\
\mathrm{i}_{\mathrm{Lc}}
\end{array}\right]
$$

The $\alpha-\beta-0$ coordinates of load currents are converted to p-q-r coordinates as given in Equation (3).

$$
\left[\begin{array}{c}
i_{p} \\
i_{q} \\
i_{r}
\end{array}\right]=\frac{1}{v_{0 \alpha \beta}}\left[\begin{array}{ccc}
v_{0} & v_{\alpha} & v_{\beta} \\
0 & \frac{-v_{0 \alpha \beta} v_{\beta}}{v_{\alpha \beta}} & \frac{v_{0 \alpha \beta} v_{\alpha}}{v_{\alpha \beta}} \\
v_{\alpha \beta} & \frac{-v_{0} v_{\alpha}}{v_{\alpha \beta}} & \frac{-v_{0} v_{\beta}}{v_{\alpha \beta}}
\end{array}\right]\left[\begin{array}{l}
i_{0} \\
i_{\alpha} \\
i_{\beta}
\end{array}\right]
$$

Where

$$
\begin{aligned}
& \mathrm{v}_{0 \alpha \beta}=\sqrt{\mathrm{v}_{0}^{2}+\mathrm{v}_{\alpha}^{2}+\mathrm{v}_{\beta}^{2}} \\
& \mathrm{v}_{\alpha \beta}=\sqrt{\mathrm{v}_{\alpha}^{2}+\mathrm{v}_{\beta}^{2}} .
\end{aligned}
$$

To achieve sinusoidal source currents and balanced condition even under non-linear loads, the compensation reference currents are calculated using Equation (6), Equation (7) and Equation (8).

$$
\begin{aligned}
& \mathrm{i}_{\mathrm{Cp}}^{*}=\tilde{\mathrm{r}_{\mathrm{p}}} \\
& \mathrm{i}_{\mathrm{Cq}}^{*}=\mathrm{i}_{\mathrm{q}}=\widetilde{\mathrm{r}_{\mathrm{q}}}+\overline{\mathrm{i}_{\mathrm{q}}} \\
& \mathrm{i}_{\mathrm{Cr}}^{*}=\mathrm{i}_{\mathrm{r}}+\frac{\mathrm{i}_{\mathrm{p} v_{0}}}{\mathrm{v}_{\alpha \beta}}
\end{aligned}
$$


Current $i_{p}=\bar{i}_{p}+\tilde{r_{p}}$ has both DC and AC components. The DC component of current $\overline{i_{p}}$ is extracted using an ANN filter unlike the low pass filter in conventional technique. The terms $\widetilde{\mathrm{r}_{\mathrm{p}}} \& \widetilde{\mathrm{r}_{\mathrm{q}}}$ contribute for the harmonic power and the term $\overline{\mathrm{i}_{\mathrm{q}}}$ contribute for the reactive power demanded by the loads. The reference zero sequence current $i_{C r}^{*}$ contributes to zero-sequence power [11]. The SAPF supplies the compensation reference currents to shape $I_{s}$. The reference compensation currents in $p-q-r$ coordinates are transformed into $\alpha-\beta-0$ coordinates using Equation (9).

$$
\left[\begin{array}{c}
i_{C o}^{*} \\
i_{C \alpha}^{*} \\
i_{C \beta}^{*}
\end{array}\right]=\frac{1}{v_{0 \alpha \beta}}\left[\begin{array}{ccc}
v_{0} & 0 & v_{\alpha \beta} \\
v_{\alpha} & \frac{-v_{0 \alpha \beta} v_{\beta}}{v_{\alpha \beta}} & \frac{-v_{0} v_{\alpha}}{v_{\alpha \beta}} \\
v_{\beta} & \frac{v_{0 \alpha \beta} v_{\alpha}}{v_{\alpha \beta}} & \frac{-v_{0} v_{\beta}}{v_{\alpha \beta}}
\end{array}\right]\left[\begin{array}{l}
i_{C p}^{*} \\
i_{C q}^{*} \\
i_{C r}^{*}
\end{array}\right]
$$

The reference compensation currents in a-b-c coordinates are determined from Equation (10).

$$
\left[\begin{array}{l}
\mathrm{i}_{\mathrm{Ca}}^{*} \\
\mathrm{i}_{\mathrm{Cb}}^{*} \\
\mathrm{i}_{\mathrm{Cc}}^{*}
\end{array}\right]=\sqrt{2 / 3}\left[\begin{array}{ccc}
\frac{1}{\sqrt{2}} & 1 & 0 \\
\frac{1}{\sqrt{2}} & \frac{-1}{2} & \frac{\sqrt{3}}{2} \\
\frac{1}{\sqrt{2}} & \frac{-1}{2} & \frac{-\sqrt{3}}{2}
\end{array}\right]\left[\begin{array}{l}
\mathrm{i}_{\mathrm{C} 0}^{*} \\
\mathrm{i}_{\mathrm{C} \alpha}^{*} \\
\mathrm{i}_{\mathrm{C} \beta}^{*}
\end{array}\right]
$$

Hysteresis current controller (HCC) produces the switching signals for the SAPF by comparing $\mathrm{i} *{ }_{\mathrm{Ca}}, \mathrm{i} *_{\mathrm{Cb}}$, $\mathrm{i}{ }^{*} \mathrm{Cc}$ and $i_{\text {shabc }}$.

\section{PROPOSED NN BASED ALLEVIATION OF $I_{s n}$}

The schematic of $\mathrm{NN}$ based $\mathrm{I}_{\mathrm{sn}}$ alleviation is depicted in Figure 3. The vector sum of the unbalanced load currents gives the neutral current. Thus the load currents of all the phases are measured and added incorporating a summer. The $i_{\text {sn }}$ value is compared with the reference value $i^{*}$ sn which is considered as zero. The output from the summer is applied to the ANN controller and thus the controller calculates the neutral current $\left(\mathrm{i}_{\mathrm{Cn}}\right)$. The HCC produces gate pulses for $1-\varphi$ APF using $\mathrm{i}^{*} \mathrm{Cn}$. Thus the proposed control strategy mitigates neutral current for an unbalanced load condition.

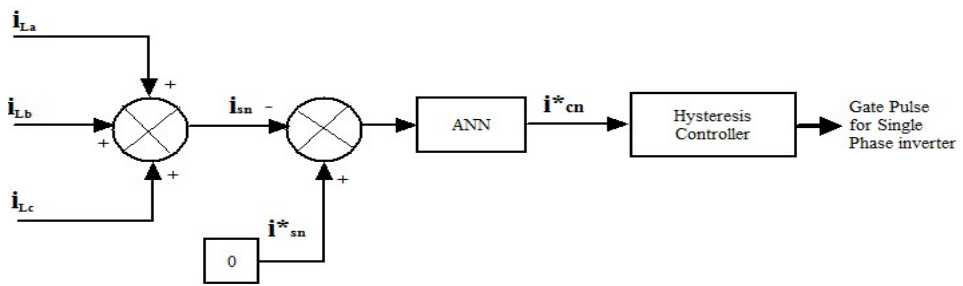

Figure 3. Schematic of NN based $\mathrm{I}_{\mathrm{sn}}$ alleviation

\section{ANN ARCHITECTURE}

Back Propagation architecture is proposed in this paper for the NN controllers. The architecture constitutes input, hidden and output layers [12], [13]. The input and output layers are decided based on the problem formulation and it is 1 for both input and output layers of NN controllers. The optimum hidden layer neurons are chosen by analyzing the performance error and training period for each value. The optimum number of neurons in the hidden layer are $12 \& 10$ for the NN controllers. 'Purelin' a linear activation function is adopted in the neurons of the output layer and to manage the non-linearity tangsigmoid activation function 'tansig' is adopted in neurons of hidden layer and output layer. The biases and weigths of the network function are varied by implementing 'Dotprod' function. The weights and biases are further finetuned by adopting 'Adaptwb' function. Levenberg-Marquardt (LM) back propagation training algorithm "trainlm" is identified to be more suitable for the stated problem. The number of training data considered are 500 and 200 for NN1 and NN2 and the number of testing data are 100 and 40 respectively. The performance goal is chosen as $1 \mathrm{e}^{-3}$. The leaning rate and testing accuracy are $0.05,98.9 \%$ for NN1 and $0.04,99.2 \%$ for 
NN2. Figure 4 depicts the performance curve of NN controllers and it is clear from the performance curve that error reaches to 0.00109 and 0.00118 after 210 and 225 epochs to attain the goal.
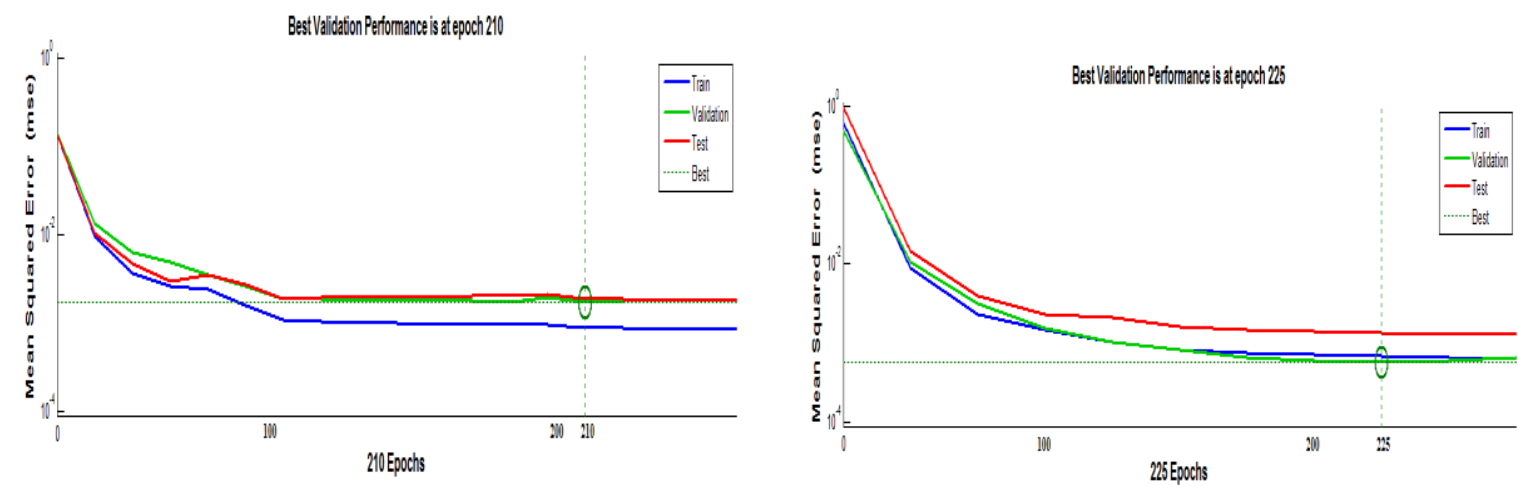

Figure 4. Performance curve of NN based p-q-r control strategy, (a) NN1, (b) NN2

\section{DISCUSSION ON SIMULATION RESULTS}

To model the SAPF, computer aided simulation is performed using MATLAB/SIMULINK. The performance of proposed NN based control algorithm in terms of THD reduction, reactive power compensation, and alleviation of neutral current is validated for varying conditions. The APF performance is also analysed for conventional controller. The performance of the APF with proposed and conventional controllers are compared. The simulation of the APF with proposed control algorithm is performed for four different source conditions as shown in Table 1. To adhere with the limitations in the number of pages simulation results are presented only for source cases II, III and IV and with one load condition. The load condition considered includes $3-\phi$ converter $\left(\alpha=20^{\circ} \& \mathrm{RL}\right.$ load $)+$ three $1-\phi$ converters (RL load) + linear unbalanced load + three 1- $\phi$ converters (RC load). To highlight the dynamic performance of the APF, the

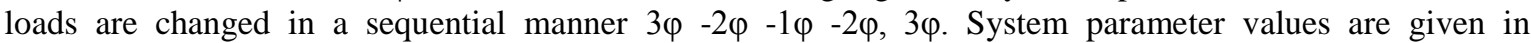
Appendix-A. The performance of SAPF with proposed control algorithm is analysed for the above mentioned supply voltage conditions with the specified load condition and the traces of (a) supply voltage (Vsabc) (b) supply currents (Isabc) (c) load currents (ILabc) (d) compensator current of 3P3W APF (Ishabc) and (e) DC bus voltage of APF (Vdc) are depicted to demonstrate its superior performance when compared to conventional controller in percentage THD reduction.

Table 1. Details of various source voltage conditions

\begin{tabular}{|c|c|c|}
\hline Case & Source voltage condition & Description \\
\hline $\mathrm{I}$ & Ideal & $415 \mathrm{~V}, 50 \mathrm{~Hz} \&\left(0^{\circ},-120^{\circ},+120^{\circ}\right)$ \\
\hline II & Unbalanced & $\begin{array}{l}\text { a) } 415 \mathrm{~V}, 50 \mathrm{~Hz} \& \text { phase unbalance }\left(20^{\circ},-120^{\circ},+120^{\circ}\right) \\
\text { b) } 20 \% \mathrm{sag} \text { for the duration }(\mathrm{t}=0.2 \mathrm{~s}-0.3 \mathrm{~s})\end{array}$ \\
\hline III & Balanced \& Distorted & $\begin{array}{l}\text { a) } 415 \mathrm{~V}, 50 \mathrm{~Hz} \&\left(0^{\circ},-120^{\circ},+120^{\circ}\right) \\
\text { b) } 20 \% \text { of } 3^{\text {rd }} \& 5^{\text {th }} \text { order harmonics }(t=0.25 \mathrm{~s}-0.4 \mathrm{~s})\end{array}$ \\
\hline IV & Unbalanced \& Distorted & $\begin{array}{l}\text { a) } 415 \mathrm{~V}, 50 \mathrm{~Hz} \& \text { phase unbalance }\left(20^{\circ},-120^{\circ},+120^{\circ}\right) \\
\text { b) } 20 \% \mathrm{sag} \text { for the duration }(\mathrm{t}=0.2 \mathrm{~s}-0.3 \mathrm{~s}) \\
\text { c) } 20 \% \text { of } 3^{\text {rd }} \& 5^{\text {th }} \text { order harmonics }(\mathrm{t}=0.25 \mathrm{~s}-0.4 \mathrm{~s})\end{array}$ \\
\hline
\end{tabular}

\subsection{Mitigation of harmonic currents}

\subsubsection{Performance of SAPF under Case: II}

Dynamic performance of the NN p-q-r control strategy based shunt APF under case: II is depicted in Figure 5. The proposed NN control strategy alleviates the $\%$ THD of the $\mathrm{I}_{\mathrm{s}}$ in phases a, b, c to $1.22 \%, 1.55 \%$ and $1.73 \%$. The THD of the $\mathrm{I}_{\mathrm{s}}$ comply with IEEE-519 standard. The measured values of $\%$ THD of source currents without APF are $22.87 \%, 24.21 \%$, and $25.97 \%$ for phases a, b, c which do not satisfy IEEE-519 recommendation. The performance of the APF is also analysed with conventional control strategy which reduces the $\%$ THD of the source currents to $7.35 \%, 6.52 \%$ and $5.90 \%$ for phases a, b, c. 

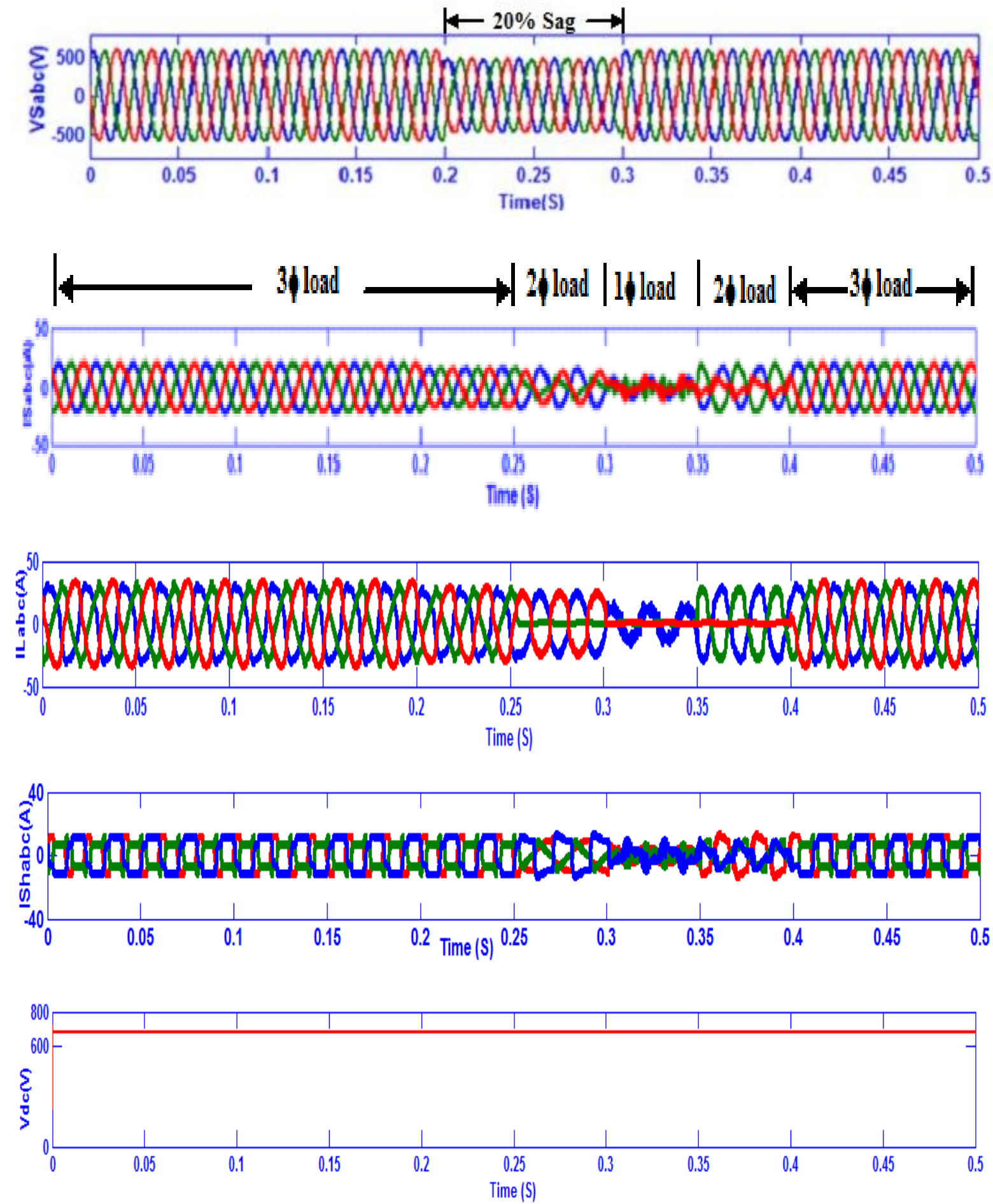

Figure 5. Performance of NN based p-q-r control theory under case: II

\subsubsection{Performance of SAPF under Case: III}

Dynamic performance of the NN p-q-r control strategy based shunt APF under case: III is depicted in Figure 6. The proposed NN control strategy alleviates the \% THD of the $\mathrm{I}_{\mathrm{s}}$ in phases a, b, c to $2.37 \%$, $1.77 \%$ and $1.48 \%$. The THD of the $\mathrm{I}_{\mathrm{s}}$ comply with IEEE-519 standard. The measured values of $\%$ THD of source currents without APF are $23.61 \%, 25.01 \%$, and $26.14 \%$ for phases a, b, c which do not satisfy IEEE519 recommendation. The performance of the APF is also analysed with conventional control strategy which alleviates the \% THD of the $\mathrm{I}_{\mathrm{s}}$ in phases $\mathrm{a}, \mathrm{b}, \mathrm{c}$ to $6.27 \%, 7.35 \%$ and $8.23 \%$. 

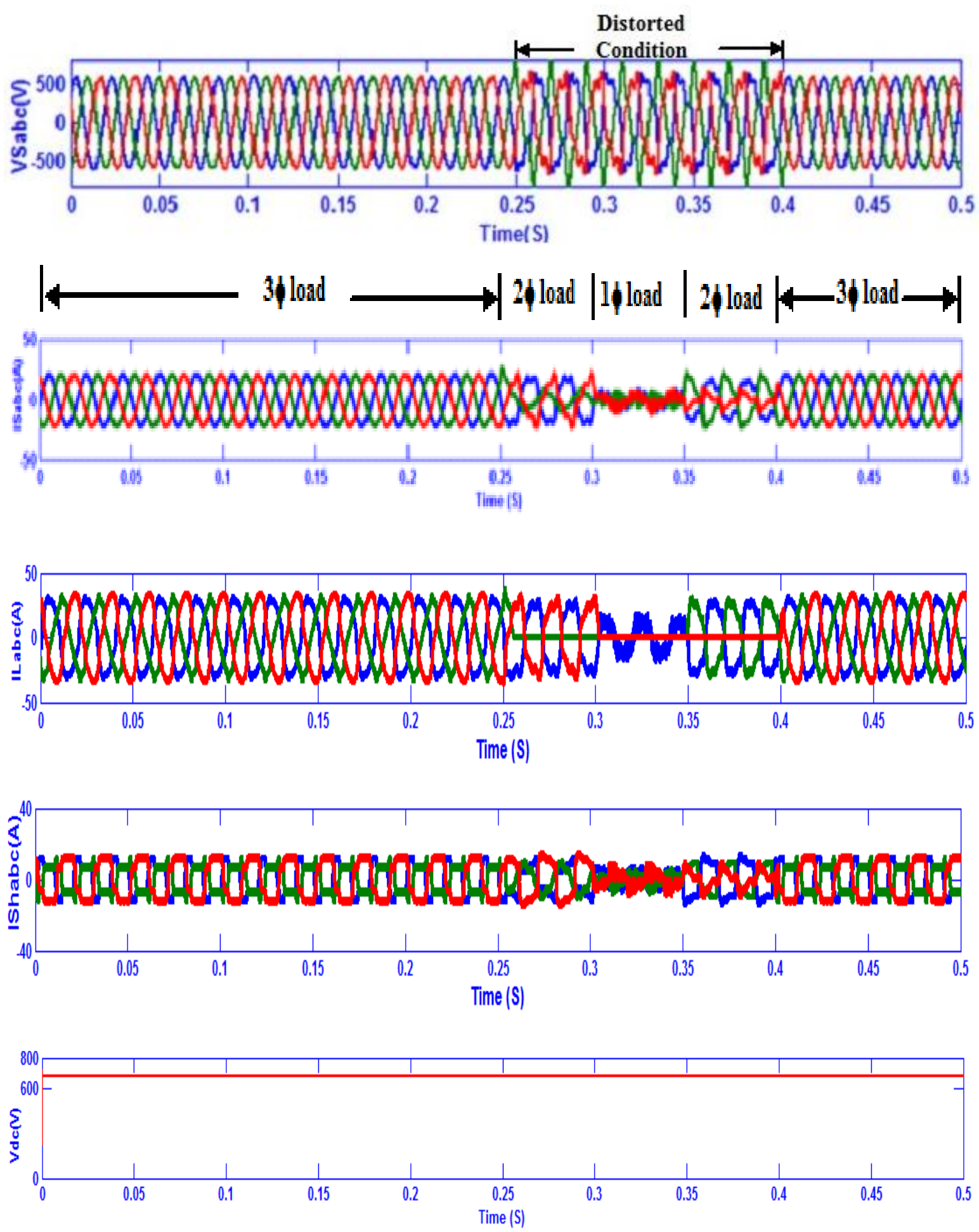

Figure 6. Performance of NN based p-q-r control theory under case: III

\subsubsection{Performance of SAPF under Case: IV}

Dynamic performance of the NN p-q-r control strategy based shunt APF under case: IV is depicted in Figure 7. The proposed NN control strategy alleviates the \% THD of the $\mathrm{I}_{\mathrm{s}}$ in phases a, b, c to $2.23 \%$, $1.62 \%$ and $2.03 \%$. The THD of the $\mathrm{I}_{\mathrm{s}}$ comply with IEEE-519 standard. The measured values of $\%$ THD of source currents without APF are $22.37 \%, 24.91 \%$, and $27.32 \%$ for phases a, b, c which do not satisfy IEEE519 recommendation. The performance of the APF is also analysed with conventional control strategy which alleviates the \% THD of the $\mathrm{I}_{\mathrm{s}}$ in phases $\mathrm{a}, \mathrm{b}, \mathrm{c}$ to $7.28 \%, 8.41 \%$ and $7.73 \%$. 

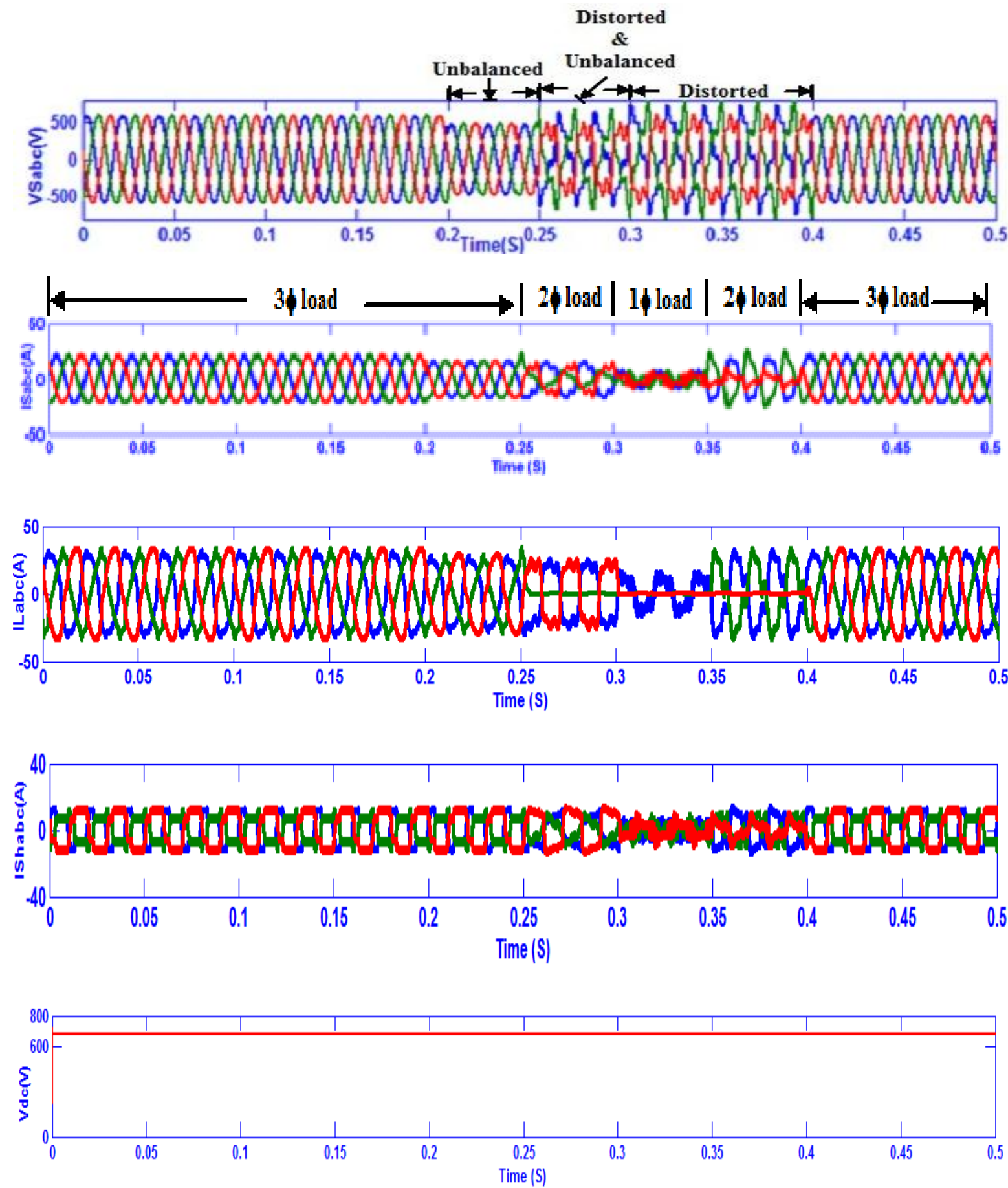

Figure 7. Performance of NN based p-q-r control theory under case: IV

Table 2. Performance comparison of SAPF

\begin{tabular}{|c|c|c|c|c|c|c|c|c|c|c|c|}
\hline \multirow{3}{*}{$\begin{array}{l}\text { Source } \\
\text { Conditions }\end{array}$} & \multicolumn{3}{|c|}{$\%$ THD } & \multicolumn{4}{|c|}{ Proposed Controller } & \multicolumn{4}{|c|}{ Conventional Controller } \\
\hline & \multirow[t]{2}{*}{$\mathrm{I}_{\mathrm{La}}$} & \multirow[t]{2}{*}{$\mathrm{I}_{\mathrm{Lb}}$} & \multirow[t]{2}{*}{$\mathrm{I}_{\mathrm{Lc}}$} & \multicolumn{3}{|c|}{$\%$ THD } & \multirow{2}{*}{$\begin{array}{l}\mathrm{V}_{\mathrm{dc}} \\
(\mathrm{V})\end{array}$} & \multicolumn{3}{|c|}{$\%$ THD } & \multirow{2}{*}{$\begin{array}{l}\mathrm{V}_{\mathrm{dc}} \\
(\mathrm{V})\end{array}$} \\
\hline & & & & $\mathrm{I}_{\mathrm{Sa}}$ & $\mathrm{I}_{\mathrm{Sb}}$ & $\mathrm{I}_{\mathrm{Sc}}$ & & $\mathrm{I}_{\mathrm{Sa}}$ & $\mathrm{I}_{\mathrm{Sb}}$ & $\mathrm{I}_{\mathrm{Sc}}$ & \\
\hline Case I & 20.63 & 23.53 & 24.97 & 0.95 & 0.85 & 1.33 & 680 & 5.8 & 6.1 & 5.7 & 679 \\
\hline Case II & 22.87 & 24.21 & 25.97 & 1.22 & 1.55 & 1.73 & 680 & 7.35 & 6.52 & 5.90 & 679 \\
\hline Case III & 23.61 & 25.01 & 26.14 & 2.37 & 1.77 & 1.48 & 680 & 6.27 & 7.35 & 8.23 & 679 \\
\hline Case IV & 22.37 & 24.91 & 27.32 & 2.23 & 1.62 & 2.03 & 680 & 7.28 & 8.41 & 7.73 & 679 \\
\hline
\end{tabular}




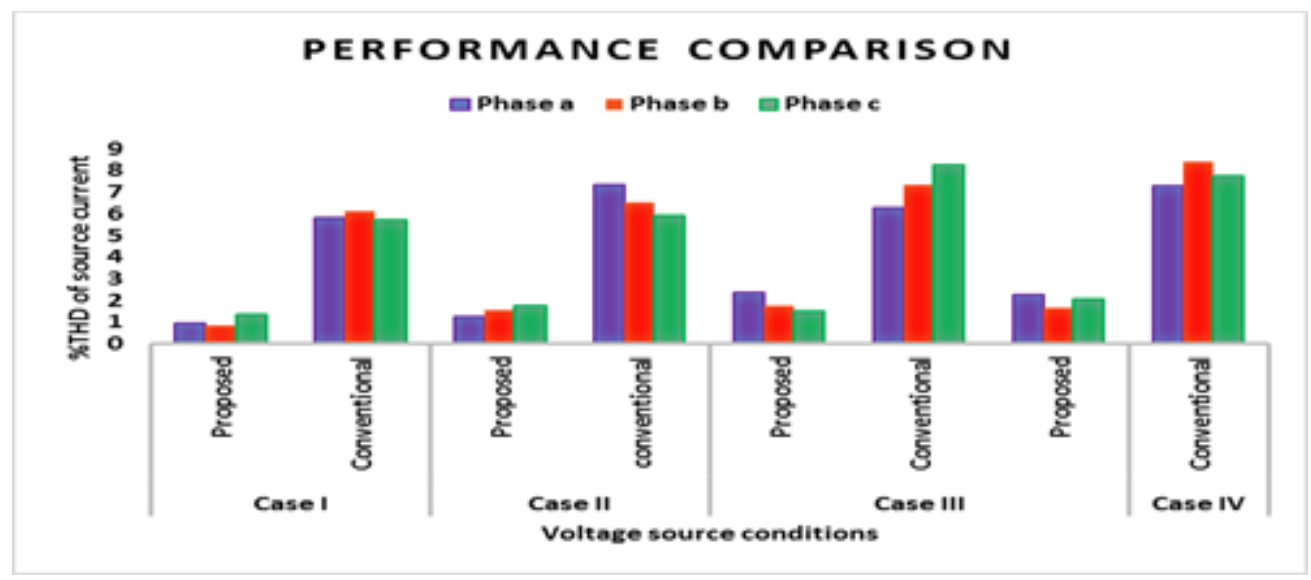

Figure 8. Comparison of \% THD of supply current under various voltage source conditions

The efficacy of the NN based proposed control algorithm for SAPF, is jusitfied from the following observations made through the simulation results. (a) The source currents are balanced, sinusoidal and the power factor is maintained close to unity even for varying conditions. (b) After the compensation of harmonic currents the THD of source currents are less than 5\% satisfying the limits suggested by power quality standards. (c) The $\mathrm{V}_{\mathrm{dc}}$ is regulated tightly at $680 \mathrm{~V}$. d) The performance of the NN controller is superior to that of conventional controller in improving the power quality of the utility. Figure 8 and Table 2 highlight the performance of the NN based proposed control strategy for various cases of voltage source. To prove the enhanced performance of proposed system, its simulation results are compared with those of the conventional controller.

\subsection{Alleviation of neutral current}

The traces of (a) Source neutral current $\left(\mathrm{I}_{\mathrm{sn}}\right)$ (b) Load neutral current $\left(\mathrm{I}_{\mathrm{Ln}}\right)$ and (c) Compensation neutral current $\left(\mathrm{I}_{\mathrm{cn}}\right)$ are depicted for supply voltage cases II, III and IV to demonstrate the performance of proposed control strategy in alleviating the neutral current.

\subsubsection{Performance of SAPF under Case: II}
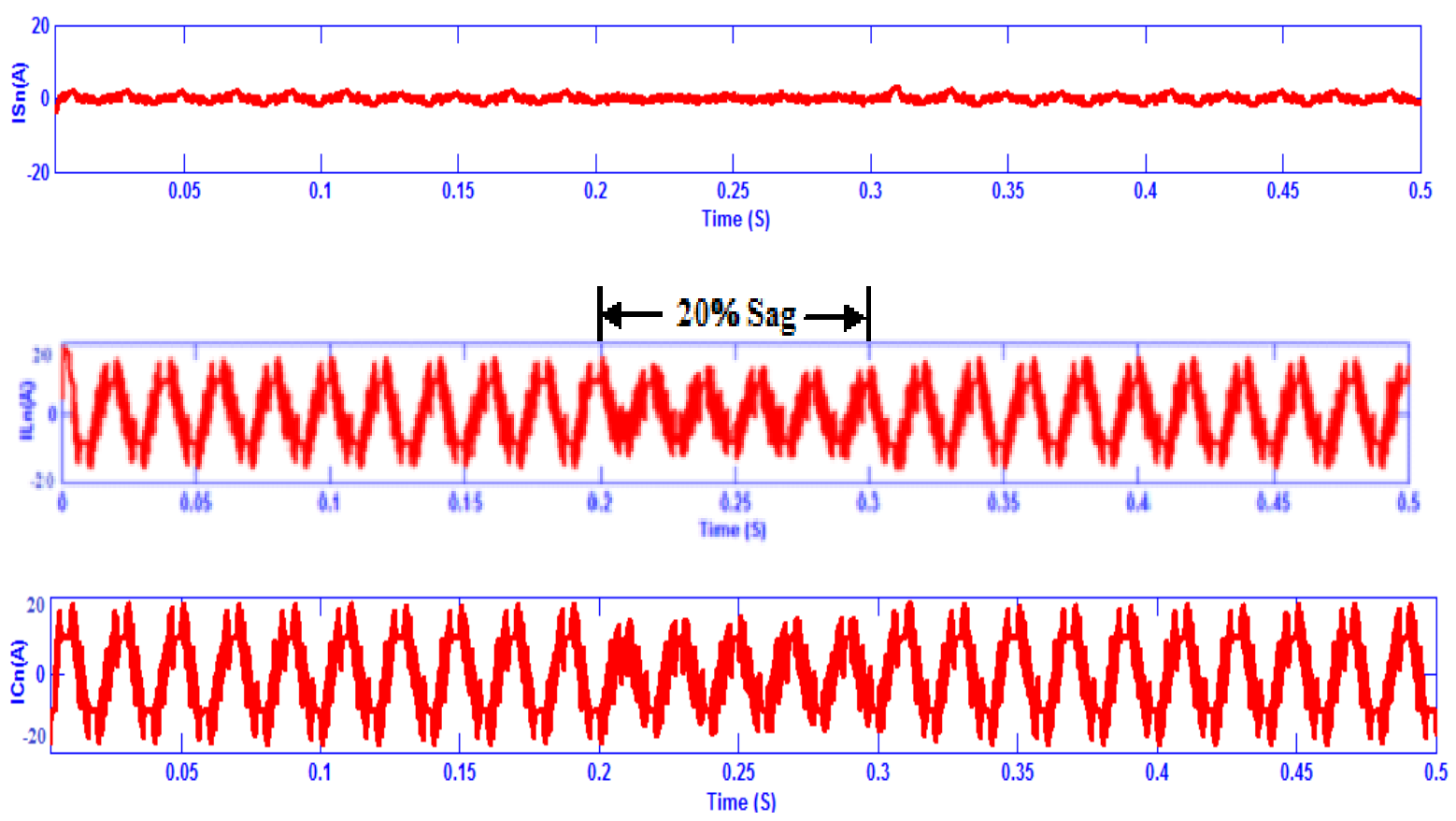

Figure 9. Performance of NN based 3P4W four leg topology under case: II 


\subsubsection{Performance of SAPF under Case: III}
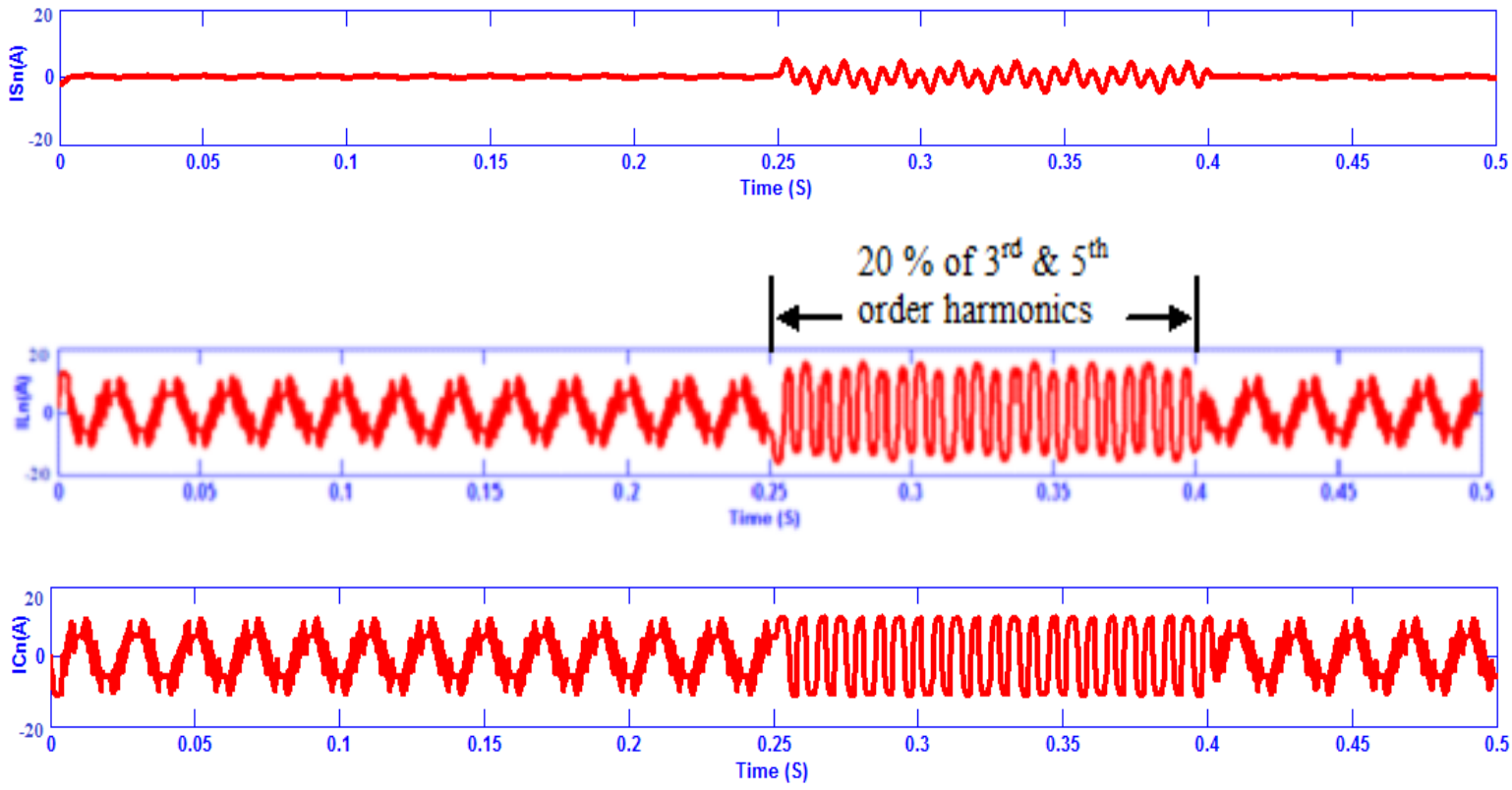

Figure 10. Performance of NN based 3P4W four leg topology under case: III

\subsubsection{Performance of SAPF under Case: IV}

It is evident from Figure 9 to Figure 11, that the NN based 3P4W APF alleviates the $\mathrm{I}_{\mathrm{sn}}$ to nearly zero. The compensation neutral current $I_{c n}$ is in phase opposition with the load neutral current $I_{L n}$, which verifies proper neutral current compensation.
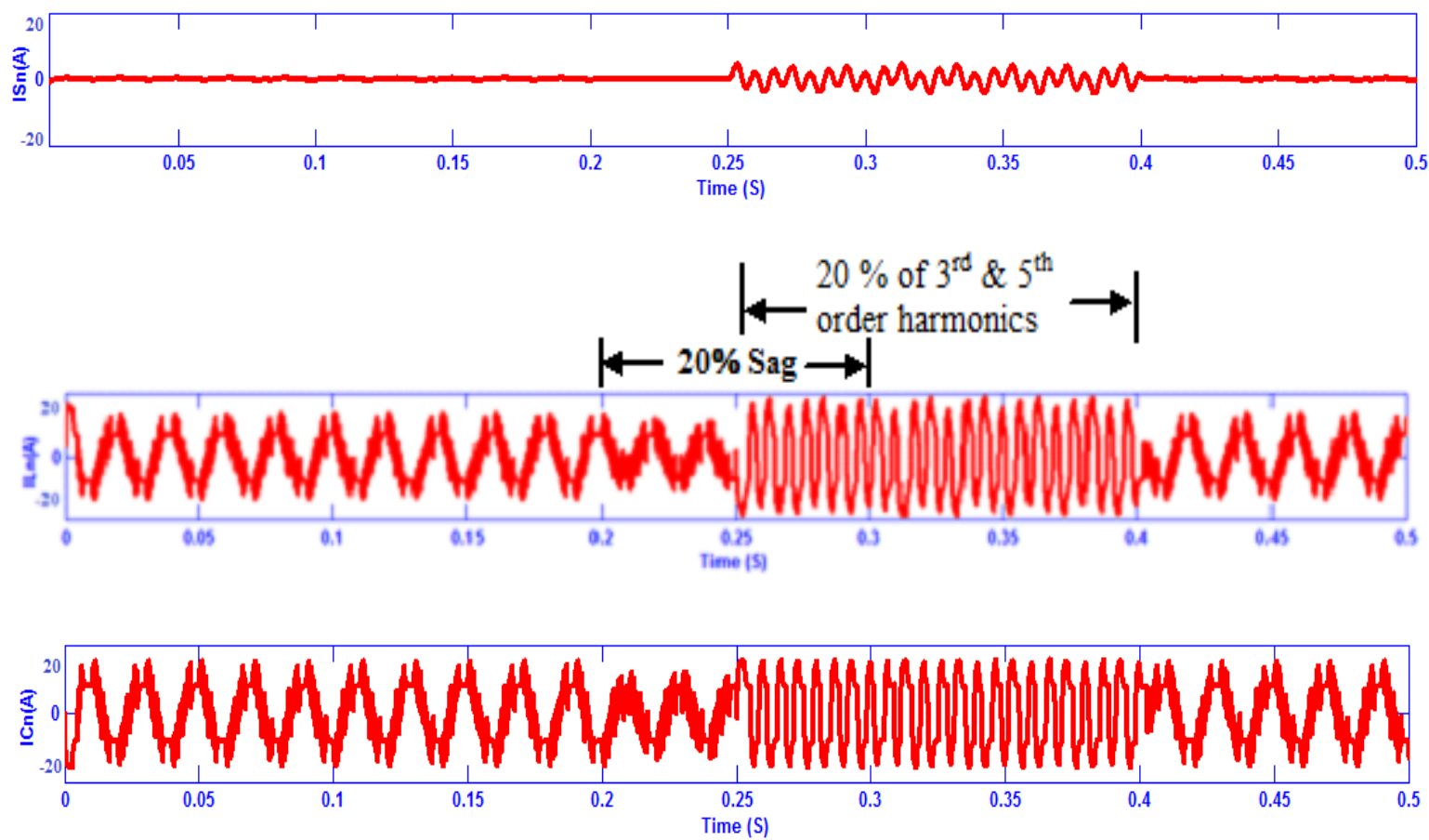

Figure 11. Performance of NN based 3P4W four leg topology under case: IV 


\section{CONCLUSION}

A NN based p-q-r control theory has been proposed for the SAPF in 3P4W distribution system. The proposed system has good compensating characteristics which includes the advantages of both cross vector and conventional p-q theory. In addition the control strategy satisfies power conservation theory and also the mathematical expression is simple and systematic. The performance of shunt APF with proposed control algorithm is evaluated under varying conditions using MATLAB/Simulink. The simulation results of SAPF with proposed and conventional controllers are compared. The traces obtained from the simulation results and tabulation prove that the proposed system is better than conventional system. The efficacy of the NN based proposed control algorithm for SAPF, is validated from the following observations made through the simulation results. a) The source currents are balanced, sinusoidal and the power factor is maintained close to unity even under varying source conditions. b) After the compensation of harmonic currents the THD of source currents are less than $5 \%$ satisfying the limits suggested by power quality standards. c) $T$ The $V_{d c}$ is regulated tightly at $680 \mathrm{~V}$. d) The performance of the NN controller is superior to that of conventional controller in improving the power quality of the utility.

\section{REFERENCES}

[1] J. K. Phipps, J. P. Nelson, and P. K. Sen, "Power Quality and Harmonic Distortion on Distribution Systems," IEEE Transactions on Industrial. Applications, vol. 30, pp. 476-484, Mar./Apr. 1994.

[2] Nor Shahida Hasan, Norzanah Rosmin, et al., "Harmonic Suppression of Shunt Hybrid Filter Using LQR-PSO based," International Journal of Electrical and Computer Engineering, vol.7,no.2,pp. 869-876, April 2017.

[3] Stuti Shukla, et al., "Implementation of Empirical Mode Decomposition Based Algorithm for Shunt Active Filter," IEEE Transactions on Industrial. Applications, vol. 53, no.3. pp. 2392-2400, May. /Jun. 2017.

[4] Bineeta Mukhopadhyay, Rajib Kumar Mandal, Girish Kumar Choudhary, "Voltage Compensation In Wind Power System Using STATCOM Controlled By Soft Computing Techniques," International Journal of Electrical and Computer Engineering, vol.7,no.2,pp. 667-680, April 2017.

[5] Prakash Chittora, Alka Singh et al., "Gauss-Newton -based Fast and Simple Recursive Algorithm for Compensation using Shunt Active Power Filter," IET Generation, Transmission and Distribution, vol. 11, no.6. pp. 1521-1530, May 2017.

[6] Deepthi Janyavula, Satyendra Nath Saxena, "Unbalanced Variable Nonlinear Load Compensation Using Multiple Shunt Active Filters," International Journal of Electrical and Computer Engineering, vol.5,no.5,pp. 896-904, Oct. 2015.

[7] Mehmet Ucar, Engin Ozdemir, "Control of a 3-phase 4 leg Active Power Filter under Non-ideal Mains Voltage Condition," Electrical Power system research, pp 58-73, 2008.

[8] Sreenivasarao D, Pramod Agarwal, Biswarup Das. "A T-connected Transformer Based Hybrid D-STATCOM for Three-phase, Four Wire Systems. Electrical Power and Energy Systems", pp.44:964-970, 2013.

[9] Rahul Kumar, Ikhalq Hussain et al., " Three-Phase Single-Stage Grid Tied Solar PV ECS using PLL-less Fast CTF Control Technique,” IET Power Electronics, vol. 10, no.2. pp. 178-188, Feb 2017.

[10] H. Kim, F. Blaabjerg, and B. Bak-Jensen, "Spectral Analysis of Instantaneous Powers in Single-Phase and Threephase Systems with use of p-q-r theory," IEEE Transactions on Power Electronics, vol. 17, pp. 711-720, Nov. 2002

[11] H. Kim, F. Blaabjerg, B. Bak-Jensen,Jaeho Choi "Instantaneous Power Compensation in Three-phase Systems by using p-q-r Theory," IEEE Transactions on Power Electronics, vol. 17, pp. 701-710,Sep. 2002.

[12] J.Jayachandran and R. Murali Sachithanandam, "Neural Network-Based Control Algorithm for DSTATCOM Under Nonideal Source Voltage and Varying Load Conditions," Canadian Journal of Electrical and Computer Engineering, vol.38, no. 4 pp.307-317, Fall 2015.

[13] J.Jayachandran and R. Murali Sachithanandam, "Performance investigation of artificial intelligence based controller for three phase four leg shunt active filter", Frontier in Energy vol. 9, no.4, pp.446-460, 2015.

\section{APPENDIX A}

$\mathrm{Vs}=415 \mathrm{~V}, 50 \mathrm{~Hz}, \mathrm{Rs}=0.02 \Omega, \mathrm{L}_{\mathrm{s}}=1.6 \mathrm{mH}, \mathrm{C}=3000 \mu \mathrm{F}$, Linear load $=30.5 \mathrm{kVA}, 25.2 \mathrm{kVA}$, $34.7 \mathrm{kVA}$, Non-linear load $\mathrm{R}=2 \Omega, \mathrm{L}=5 \mathrm{mH}, \mathrm{C}=9 \mu \mathrm{F}$, interfacing inductor $=2.5 \mathrm{mH} /$ phase. 


\section{BIOGRAPHIES OF AUTHORS}

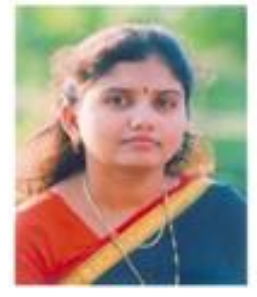

S. Malathi was born in India. She received the B.E. degree in Electrical and Electronics Engineering from Bharathidasan University, Tamilnadu in 2000 and M.Tech. degree in Power Electronics and Drives from SASTRA University, Thanjavur Tamilnadu in 2004. Presently Pursuing Ph.D. in the area of Power Electronics at SASTRA University, Thanjavur, India. Her area of interest are Power Converters and power quality.

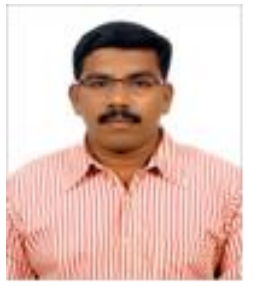

J. Jayachandran was born in India. He received the B.E. degree in Electrrical and Electronics Engineering from Kongu Engineering college, Tamilnadu in 1999 and M.E. degree in Power Electronics and drives from Bharathidasan University, Thanjavur Tamilnadu in 2000. Presently Pursuing Ph.D. in the area of Power Electronics at SASTRA University, Thanjavur, India. His area of interest are Power Quality, Power Converters and Renewable Energy Sources. 